\title{
Impact of social environment on variation in menstrual cycle length in captive female olive baboons (Papio anubis)
}

\author{
Cécile Garcia, Phyllis C Lee ${ }^{1}$ and Lyliane Rosetta \\ Laboratoire de dynamique de l'évolution humaine, CNRS UPR 2147, 44 rue de l'Amiral Mouchez, 75014 Paris, \\ France and ${ }^{1}$ Department of Psychology, University of Stirling, Scotland FK9 4LA, UK \\ Correspondence should be addressed to C Garcia who is now at Department of Ecology, Primate Research Institute, Kyoto \\ University, 41-2 Kanrin, Inuyama, Japan; Email: cecile@pri.kyoto-u.ac.jp
}

\begin{abstract}
Factors affecting menstrual cycles and conception were explored for captive female olive baboons. We evaluated the relationship between the social environment and adequacy of the menstrual cycle in 55 non-conceptive and 21 conception cycles from 23 females. More abnormal cycles were expected for low-status females, and social stress levels were associated with variation in menstrual cycle length. Mean cycle length was 39.9 days (median $=38$ ) with a mean follicular phase duration of 23.7 (median $=22)$ days. The duration of the follicular phase was more variable than that of the luteal phase (mean $=15.8$ days). The first cycle after postpartum resumption of cycling was not markedly different from subsequent cycles in terms of duration or probability of conception. Dominance rank was one significant factor affecting female fertility. Low-ranking females experienced more cycles prior to conception, longer cycles once cycling was well established and had smaller sexual swellings (anogenital area) than did high-ranking females. Both acute and chronic stresses may play important roles in fertility outcomes for these baboons and further research is needed to understand the role of stress and subtle menstrual cycle abnormalities in female mammal fertility.

Reproduction (2008) 135 89-97
\end{abstract}

\section{Introduction}

In primates, the energetic and social environment of females is thought to have a profound influence on reproductive function and fertility. The effects of energetics and more precisely energy intakes on reproductive functioning have been demonstrated in studies on women and other mammals (Cameron \& Nosbisch 1991, Cameron et al. 1991, Rosetta 1993, Wade et al. 1996, Dewey 1998). Intra- and interindividual differences in reproductive performance may also be due to variation in physical activity (Loucks et al. 1989, Rosetta et al. 1998, Chen \& Brzyski 1999, Williams et al. 2001), age (Strum \& Western 1982, Wasser et al. 1998, Martin et al. 2003), and offspring survival (Altmann et al. 1988). The menstrual cycle is often used as a descriptor of women's reproductive hormone competence, with a range of variation associated with conception probabilities and spontaneous abortions (Small et al. 2006).

In addition to individual, occupational, health, and energetic influences on menstrual cycles and fertility, social constraints can act to impair reproductive function (Abbott 1992, Packer et al. 1995) ranging from a moderate diminution of reproductive hormone secretion to a complete suppression of fertility (Cameron 1997).
Experience of acute psycho-social stress has been associated with duration and amount of menstrual bleeding, and menstrual cycle aberrations or irregularities such as oligomeorrhea, anovulatory cycles, and lutealphase deficiencies (Harlow \& Campbell 1996, Chrousos et al. 1998, Fenster et al. 1999, Sanders \& Bruce 1999).

In humans, it can sometimes be difficult to monitor full menstrual cycles over successive and lengthy periods for reasons such as the use of contraceptives, pregnancy, or illness. However, observations made in captive colonies of non-human primates can circumvent many of these difficulties. The reproductive hormone profiles across the menstrual cycle of the baboon are analogous to those of women (Hendrickx \& Kraemer 1969, Stevens 1997) and the menstrual cycle can be easily determined by monitoring turgescence of the sex skin. This species is therefore a very good model for understanding factors affecting the regulation of fertility (D'Hooghe et al. 2004).

This paper uses 2 years of data on female menstrual cycles in a colony population of olive baboons (Papio anubis) to investigate possible effects of social status, expressed via dominance rank, age, and local environment on the menstrual cycle length, duration of follicular and luteal phases, and number of cycles before conception. In previous work on this colony (Garcia etal. 2006), we found that social dominance rank was a significant factor 
affecting female fertility, with low-ranking females having longer total intervals between subsequent births. Short postpartum amenorrhea was associated with being in mid or high rank, while the number of cycles to conception showed a tendency to be greater in low-ranking females. In the present work, we focus on the period of cycling until conception. The following question was addressed: does the length of menstrual cycle vary depending on dominance status, using this measure as a behavioral proxy for stress, and therefore do low-ranking females have menstrual cycles that differ in length from those of highranking ones? Given that age, physical condition, and social environment may all influence reproductive performance, we explore individual characteristics in relation to cycle length, as well as whether there is an effect of time from resumption of cycling on cycle length. The study was observational; during the study period, the nature of the enclosure precluded dung collection for subsequent hormone assay. In addition, baboon swellings have been used as signals (to males) of reproductive competence for the past 40 years; few studies, however, have explored the relations between the duration and phases of the cycle and the social context.

\section{Results}

\section{Menstrual cycle length}

One to ten menstrual cycles were recorded for each of the 23 target females, with a total of 79 observed cycles. The average number of cycles until conception was 3.6 (median=2.5, $\left.N_{\text {censored }}=1\right)$. Of the observed cycles, two were interrupted by partial swelling, detumescence, and re-inflation, and lasted respectively 58 and 77 days; these have been excluded from further analysis. Total cycle length could only be calculated for 55 nonconceptive cycles, as the duration of the full luteal phase could not be determined once a conception occurred $(N=22)$. Observed cycles lasted for a mean of 39.9 days (median $=38$, range $=27-69$ days, inter-quartile ranges $(\mathrm{IQR})=6.0$ days, $N=55)$.

The full duration of the first menstrual cycle after the postpartum resumption of cycling was known for 18 females (4 females conceived at first ovulation and 1 female had an interrupted first cycle). Mean first postpartum menstrual cycle length was 42.3 days. Individual variability in first menstrual cycle duration was considerable, with a range of 31-69 days (median $=38.5$; $\mathrm{IQR}=10.0$ days). Subsequent cycle lengths averaged 38.7 days $(N=37$; range $=27-61$ days; median $=37$; $\mathrm{IQR}=6.0$ days) although these were not significantly different from the length of the first postpartum cycle overall (ANOVA $F_{1,55}=1.97$, NS; Fig. 1 ).

There was no relationship between total cycle length and energy intake (estimated from total daily food intake measures per kilogram body mass; Garcia 2005; $r=0.11, N=55)$, female age $(r=0.16)$ or rank as a

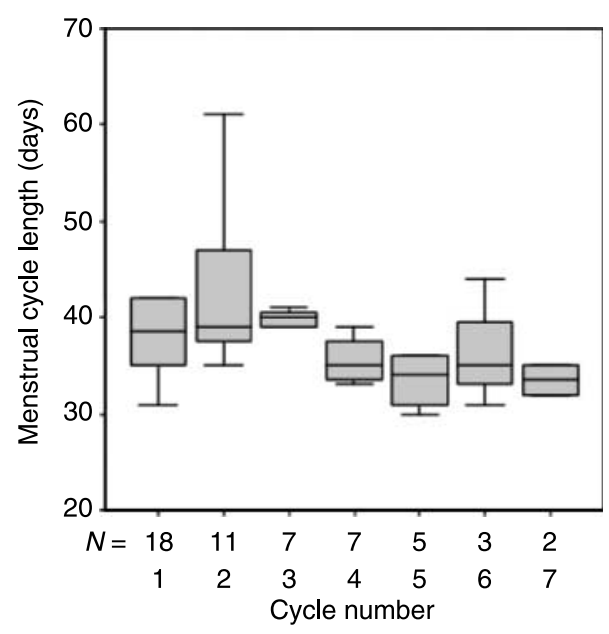

Figure 1 Duration (in days) of the menstrual cycle and its relation to the number of cycles after the end of postpartum amenorrhea. Plot shows median (bar), inter-quartile range (box), and highest and lowest values (whiskers). Each female contributed only a single value to any cycle. $N$ of females shown.

percentage of females dominated $(r=-0.08)$. Neither gestation length $(r=-0.002, N=19)$, inter-birth interval $(r=-0.136)$, nor duration of postpartum amenorrhea $(r=-0.062)$ were related to cycle length.

However, the length of successive cycles experienced by a female did differ considerably and these were also influenced by its dominance rank. Rank is a major factor affecting the number of cycles to conception, with highranking females experiencing fewer cycles than subordinates $(r=-0.428, P<0.05, N=22)$. While first cycles did not stand out overall, for each female that cycled more than once, there was a significant overall difference in length between its successive cycles (repeated measures ANOVA, sphericity assumed, $\left.F_{2,7}=15.24, P=0.004\right)$; a female's first cycle tending to be longer than its second (pairwise comparisons, $P=0.01)$. While there was no significant effect of relative rank on the first postpartum cycle, there was a negative effect of relative rank on the length of the third or greater cycle after resumption of ovarian cyclicity $\left(r_{\mathrm{s}}=-0.821, P=0.023, N=7\right)$; subordinate females had longer cycles than did dominant ones once cyclicity was well established.

\section{Follicular phase}

The follicular phase had an overall mean duration of 23.7 days, with a range of $13-53$ days (median $=22$; $N=76$; Table 1). The duration of first follicular phase after the resumption of cycling was 27.2 days (median $=25$; range $=16-53$ days; $\mathrm{IQR}=8.3$ days, $N=21$ ). Follicular phase length in subsequent cycles was 22.4 days $(N=55$; median $=21$, range $=13-45$ days; $\mathrm{IQR}=7.5$ days), significantly shorter than that of the first cycle $\left(F_{1,76}=4.32\right.$, $P=0.041$; Fig. 2). There was no relationship between the 
Table 1 Duration of the component parts of the follicular phase (days) for all cycles, non-conceptive and conceptive cycles separately in female olive baboons.

\begin{tabular}{|c|c|c|c|}
\hline & $N$ & Median & Range (IQ range ${ }^{\mathrm{a}}$ ) \\
\hline \multicolumn{4}{|l|}{ All cycles } \\
\hline Menstruation & 52 & 4.00 & $1-8(2)$ \\
\hline Menstrual flat ${ }^{b}$ & 52 & 5.00 & $1-32(4)$ \\
\hline Inflating & 76 & 9.00 & $4-23(4.75)$ \\
\hline Fully tumescent & 76 & 10.00 & $3-43(4.75)$ \\
\hline \multicolumn{4}{|c|}{ Non-conceptive cycles } \\
\hline Menstruation & 34 & 4.00 & $2-8(2)$ \\
\hline Menstrual flat & 34 & 6.00 & $2-32(4.5)$ \\
\hline Inflating & 55 & 9.00 & $4-23(6)$ \\
\hline Fully tumescent & 55 & 10.00 & $3-43(5)$ \\
\hline \multicolumn{4}{|l|}{ Conceptive cycles } \\
\hline Menstruation & 18 & 3.00 & $1-7(1.5)$ \\
\hline Menstrual flat & 18 & 5.00 & $1-14(3.25)$ \\
\hline Inflating & 21 & 8.00 & $5-20(3.5)$ \\
\hline Fully tumescent & 21 & 11.00 & $5-20(3)$ \\
\hline
\end{tabular}

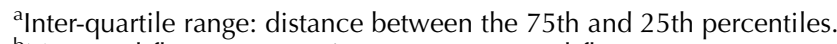
${ }^{\mathrm{b}}$ Menstrual flat $=$ menstruation + post-menstrual flat.

mean duration of follicular phase and a female's latency to resumption of cycling $(r=-0.178, N=19)$.

Follicular phase length was significantly shorter for conceptive cycles (median $=22.0$ days) in comparison with non-conceptive cycles (median $=24.0$ days; Wilcoxon test, $Z=-2.13, P=0.033, N=18$; Fig. 3). Females in the larger park (park 5) experienced significantly longer follicular phases across all cycles than did those in park $2\left(F_{1,76}=5.68, P=0.021\right)$. There was no significant effect of female age or rank, nor any interaction between these variables.

\section{Menses}

When detection of menses was possible, menstruation periods had a median duration of 4.0 days $(N=52$;

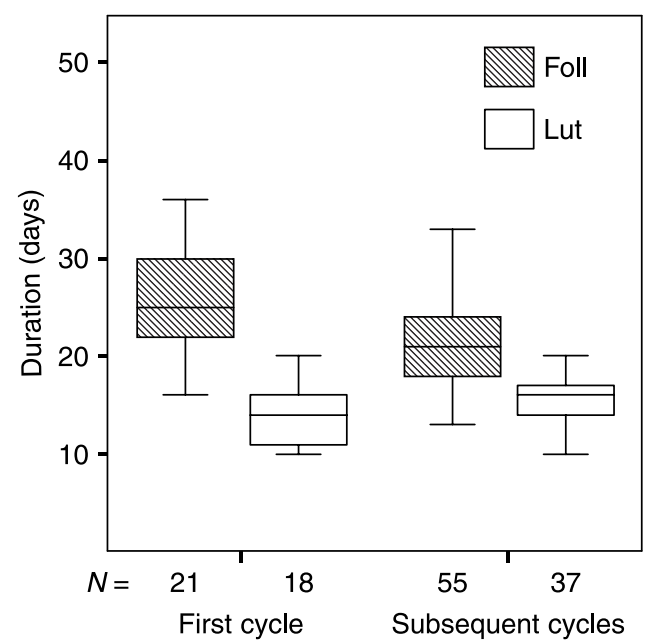

Figure 2 Duration (in days) of the follicular and luteal phases for the first postpartum cycle and the subsequent cycles. Plot shows median (bar), inter-quartile range (box), and highest and lowest values (whiskers). Each female contributed only a single value to any cycle. $N$ of females shown.

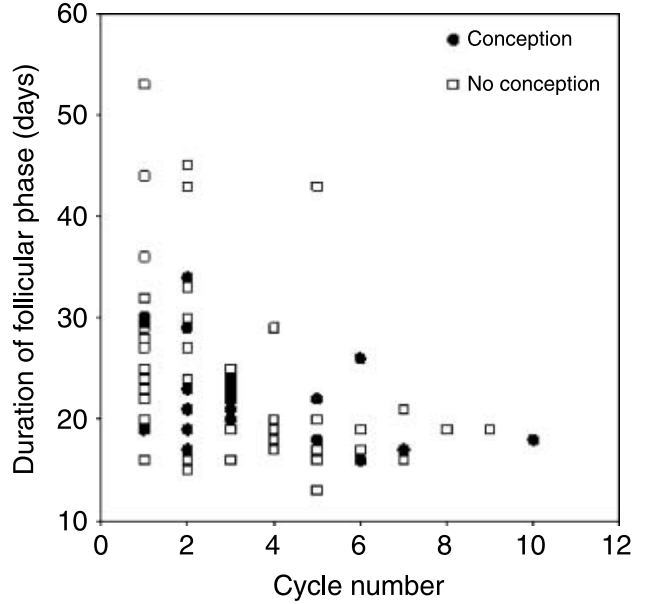

Figure 3 Duration (in days) of the follicular phase for conceptive and non-conceptive cycles according to cycle number in female baboons.

range, 1-8 days). There was a negative relationship between a female's relative rank and its total duration with no swelling, i.e., the duration of menses plus the duration of post-menstrual flat $\left(r_{\mathrm{s}}=-0.475, P=0.040\right.$, $N=19$ ); lower ranking females spent more time in an average cycle with no swelling. Females with longer menses and fewer swelling days also experienced more cycles before conceiving $\left(r_{\mathrm{s}}=0.547, P=0.019, N=18\right)$.

\section{Follicular phase morphological changes to the anogenital area $(A G A)$}

Conceptive cycles differed from non-conceptive cycles with a shorter duration of inflating and fully tumescent phases for conceptive cycles (inflating phase: MannWhitney $Z=-3.21, P=0.001, N=18$; fully tumescent phase: $Z=-2.08, P=0.037, N=18$ ).

The duration of the first inflating phase after resumption of cycling was significantly longer than that in subsequent cycles $(Z=-2.95, P=0.003, N=11)$. For the fully tumescent phase, the first maximal swelling tended to be longer than were subsequent ones $(Z=-1.73$, $P=0.083, N=11$ ).

Females in park 5 had longer inflating and fully tumescent phases than did those in park 2 (inflating phase: $U=18.50, P=0.047, N=19$; fully tumescent phase: $U=17.50, P=0.038, N=19)$.

\section{Luteal phase}

The duration of the entire luteal phase could only be examined in non-conceptive cycles because subsequent menses were absent in conceptive cycles (Table 2). The non-conceptive luteal phase had a mean duration of 15.8 days (median $=15.0$ days; $N=55$; range $=10-35$ days; $I Q R=4.0$ days). While the duration of the first luteal phase after resumption of ovarian cyclicity differed only slightly from duration in subsequent cycles 
Table 2 Duration of the component parts of the luteal phase (days) using non-conceptive and conceptive cycles in female olive baboons.

\begin{tabular}{lccc}
\hline & $\mathbf{N}$ & Median & Range (IQ range) \\
\hline $\begin{array}{l}\text { All cycles } \\
\quad \text { Deflate }\end{array}$ & 76 & 4.00 & $2-16(2)$ \\
$\begin{array}{l}\text { Non-conceptive cycles } \\
\quad \text { Deflate }\end{array}$ & 55 & 4.00 & $2-16(2)$ \\
$\begin{array}{l}\text { Flat } \\
\text { Conceptive cycles }\end{array}$ & 55 & 10.00 & $2-28(6)$ \\
$\quad$ Deflate & 21 & 4.00 & $2-7(2)$ \\
\hline
\end{tabular}

${ }^{\mathrm{a}}$ Full detumescence which is only exhibited in non-conceptive cycles.

(14.0 vs 16.0 days; ANOVA $F_{1,55}=1.91$, NS; Fig. 2 ), the period of full detumescence during the first postpartum cycle was significantly shorter than that in subsequent cycles $(Z=-2.70, P=0.007, N=11)$.

Mothers of daughters had a longer luteal phase than did mothers of sons (16.0 vs 13.6 days; $F_{1,55}=8.02$, $P=0.008)$. In addition, older and low-ranking mothers had longer luteal phases $\left(F_{3,54}\right.$ age rank $=2.91$, $P=0.048)$. Thus, there appeared to be some socially or behaviorally mediated effects on the duration of the luteal phase. The 'daughter effect' was not due to a difference in offspring sex ratio among old or lowranking mothers, with $8 \mathrm{M}: 9 \mathrm{~F}$ for mid- and low-ranking mothers across all ages.

\section{Size of the anogenital swelling}

There was considerable variation among females in the size of the anogenital swelling (Fig. 4), some of which was associated with absolute size. Swelling size was positively related to body mass $\left(r_{\mathrm{s}}=0.545, P=0.016, N=19\right)$ and crown-rump length (CRL; $\left.r_{\mathrm{s}}=0.595, P=0.009, N=18\right)$. As a result, all associations between swelling size and reproductive parameters were made with partial correlations, holding body size (CRL) constant.

There was a negative correlation between inter-birth interval and AGA width measured during the postpartum amenorrheic flat stage (Kendall's $\tau=-0.571$, $P=0.048, N=8$ ).

During the fully tumescent phase, females with smaller swelling sizes had a longer cycle duration (Kendall's $\tau=-0.500, P=0.034, N=11$ ). There was also an effect of relative rank, with maximal swelling size increasing with dominance rank (Kendall's $\tau=0.477$, $P=0.042, \quad N=11)$. Low-ranking females had significantly smaller swelling size $(25.9 \pm 0.2 \mathrm{~cm})$ than did mid-ranking females $(32.4 \pm 3.2 \mathrm{~cm}, U=0.00$, $P=0.046, N=8$ ), whereas high-ranking females tended to have larger swelling sizes than low-ranking counterparts $(U=0.00, P=0.083, N=5)$. Since there are no rank-related differences in body size among the females (Garcia et al. 2006), and absolute size was taken into account, these associations are independent of female body size.

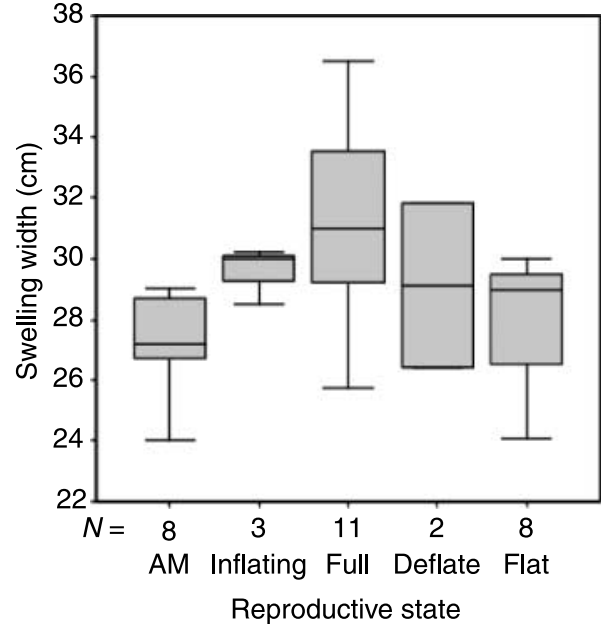

Figure 4 Swelling width (in centimeters) by reproductive state (AM, postpartum amenorrhea as baseline AGA size, inflating, fully tumescent, deflate, flat). Plot shows median (bar), inter-quartile range (box), and highest and lowest values (whiskers). $N$ of females shown.

\section{Discussion}

In our captive sample, the average menstrual cycle length of $\sim 40$ days was similar to that reported previously for other Papio species (Stevens 1997, Wasser et al. 1998, Martin et al. 2003, Gesquiere et al. 2007). The first postpartum cycle was more variable but not longer than subsequent cycles. Conception resulted during $17 \%$ of first cycles, in comparison with an average likelihood of $26 \%$ in any cycle (Garcia et al. 2006). In this captive colony, the first cycle after resumption of cycling did not appear to be markedly different from subsequent cycles in terms of hormonal competence and ovulatory probability. Among human couples planning their first pregnancy, conception probabilities across cycles are similar to those observed in these baboons (Bonde et al. 1998: 15.6, 17.6, and $13.9 \%$ for menstrual cycles 1,2 , and 3 respectively).

The number of cycles to conception differed between parks with females in park 2 having significantly more cycles prior to conception that did those in park 5 (for more details, see Garcia et al. 2006). We suggested that either higher male fertility in park 5 or less attractive sexual swellings for females in park 2 might be causal. No effect of park on menstrual cycle length was found here and there was no difference in the swelling width between the two parks, which strengthens our suggestion concerning male quality. Males, rather than females, in park 5 may be more fertile, leading to higher reproductive rates.

\section{Dominance rank and menstrual cycle length}

Observations on long-distance runners undergoing chronic energetic or nutritional stresses during endurance training found an increased incidence of menstrual 
disturbances, in terms of a longer follicular phase in ovulatory cycles, higher percentage of anovulatory cycles in those women with irregular cycles, and finally an increased percentage of oligomenorrhea and amenorrhea (Rosetta 1993). Although such chronic energetic stress differs considerably from psycho-social stresses resulting from behavioral interactions, we suggest that low-ranking females are exposed to chronic social stresses which may make them more likely to experience variance in the duration of their menstrual cycles.

While the length of the first two cycles after resumption of cycling did not differ among females of different status, dominance rank was negatively associated with duration of the third or greater menstrual cycle for these baboons. In part, this is due to the marked effect of rank on conception probability, suggesting that social stress plays a role in lengthening the time to conception increasing the variance in cycle length. Long cycles are also more common among women with depression (Rowland et al. 2002).

Both acute and chronic stresses appear to play important roles in fertility outcomes for baboons. The hypothalamic-pituitary-adrenal (HPA) axis activated during acute stress episodes could affect fertility by suppressing gonadotropin-releasing hormone $(\mathrm{GnRH})$ secretion. One mechanism by which stress is inhibitory to the $\mathrm{GnRH}$ pulse generator is through the activation and the central release of neuroendocrine components of the HPA axis (Ferin 1999). The inhibitory effects of acute stress on reproductive neuroendocrine activity have been demonstrated in sheep. Breen \& Karsch (2006) have shown that, in the gonadectomized ewe, stress-like levels of cortisol acutely inhibited the release of luteinizing hormone (LH) by reducing pituitary responsiveness to both endogenous and exogenous $\mathrm{GnRH}$ pulses, rather than by inhibiting $\mathrm{GnRH}$ release itself. Studies in ovary-intact ewes showed an alternative mode of cortisol action. During the follicular phase of the estrous cycle, cortisol reduced LH pulse frequency, most likely via the inhibition of GnRH pulsatility, which compromised timely expression of the preovulatory estradiol rise and $\mathrm{LH}$ and follicle-stimulating hormone (FSH) surges (Breen et al. 2005). The suppression of frequency provided indirect evidence that cortisol could act centrally to inhibit GnRH secretion. This suggested that the ovarian steroid milieu during the follicular phase enabled cortisol to suppress pulsatile GnRH secretion.

\section{Factors affecting the duration of follicular and luteal phases}

Variability in the length of the follicular phase was marked in these female olive baboons, while the luteal phase was more constant (see also Dixson 1998, van Schaikh et al. 1999). In particular, the first follicular phase after resumption of ovarian cyclicity was longer than those during subsequent cycles as noted for macaques and mandrills (Thierry et al. 1996, Setchell \& Wickings 2004). Sex-skin swelling appeared to proceed more slowly to the fully tumescent phase in the first cycle. Setchell \& Wickings (2004) suggested that this lengthening may be due to an increase in the time needed to build-up the endometrium following the ovarian quiescence of postpartum amenorrhea. However, the underlying physiological mechanisms responsible for lengthening the first follicular phase remain to be determined in the absence of data on hormonal levels during this first postpartum cycle.

Follicular phase length was shorter for conceptive cycles in comparison with non-conceptive cycles, with sex-skin swelling appearing to proceed more quickly to the fully tumescent stage during conceptive cycles, in contrast to previous studies (Bercovitch 1987, Setchell \& Wickings 2004). Among women, the follicular phase accounts for most of the variation in cycle length, and short cycles tend to be associated with reduced conception probabilities as well as increasing age (see Small et al. 2006). During conceptive cycles among these baboons, old and low-ranking females had a shorter follicular phase than did younger females, as previously noted by Wasser et al. (1998). A shortened fully tumescent stage in Papio could imply earlier ovulation because ovulation is presumed to occur during the last few days of maximal tumescence (Hendrickx \& Kraemer 1969, Koyama et al. 1977, Shaikh et al. 1982).

The effects of stress on the menstrual cycle have been studied prospectively in non-human primate models (Xiao et al. 1999). Whether the stress was experienced during the follicular or during the luteal phase determined the dysfunction of the menstrual cycle (Xiao et al. 2002). An acute stress episode during the follicular phase delayed folliculogenesis, leading to an anovulatory cycle. However, if ovulation was maintained, the duration of the follicular phase increased and the integrated progesterone secretion of the luteal phase could be significantly decreased. During the luteal phase, an acute stimulation of the HPA axis was accompanied by secretory inadequacy of the corpus luteum shown by lower LH levels and a decrease in integrated luteal progesterone secretion, although luteal phase length remained unchanged (Xiao et al. 2002).

The menstrual flat state was the longest in our lowranking females. In effect, their sex-skin swelling appeared to be delayed. The late onset of sex-skin swelling could imply delayed follicular development and elevation of gonadotropins later in the cycle, given the dependence of sex-skin swelling on estradiol and FSH. Moreover, the number of cycles before conceiving was greater when the menstrual flat portion of the follicular phase was relatively long, both of which were associated with low-ranking females (see also Wasser et al. 1998). The relationship between menstruation length and fertility remains unclear. Small et al. (2006) have shown an association between long menstruation lengths and lower fecundity in 
American women, whereas in a population of rural Bolivian women, menstruation preceding a conception was longer than menstruation not followed by conception (Vitzthum et al. 2001). Duration of the menstrual period is the result of different components, such as uterine size, steroid hormones production, and prostaglandin production (Harlow \& Campbell 1996). As a result, it is difficult to identify key factors in its regulation. However, high levels of stress have been associated with dysmenorrhea or lengthening of menstruation in some human populations (Harlow \& Campbell 1996, Wang et al. 2004), suggesting that further investigation of the role of stress is warranted.

We found a negative relationship between relative rank and the duration of the luteal phase, with subordinate females having longer luteal phases. In cows, some studies have shown that prolonged luteal phase was associated with lower rates of conception and pregnancy and poorer reproductive performance (Shrestha et al. 2004). It was hypothesized that an abnormal uterine environment may prevent or suppress the secretion and release of prostaglandins $\left(\mathrm{PGF}_{2 \alpha}\right)$ by the uterine endometrium and its local transportation to the ovary, resulting in the failure of luteolysis and hence the prolonged luteal phase. Although fertility and rank are positively associated in this colony of baboons (Garcia et al. 2006), the mechanism either does not operate through luteal phase quality, or, if it does, it rests on more subtle hormonal levels than those reflected in AGA swelling stages. Close hormonal monitoring of the menstrual cycle to assess exposure to chronic and acute stressors and physiological changes is currently underway using non-invasive sampling (A Daspre, unpublished observations).

\section{Sexual swellings and reproductive competences}

Sex-skin swellings occur in the majority of catarrhine primates living in multi-male, multi-female groups (Dixson 1998), such as baboons. There is a consensus that sexual swellings have evolved in the context of sexual selection and that they increase female attractiveness and stimulate male sexual arousal (Girolami \& Bielert 1987). However, considerable disagreement exists on their functional significance, reflected in the number of competing hypotheses (see reviews in Dixson 1998, Nunn 1999, Stallmann \& Froehlich 2000). The reliable-quality indicator hypothesis (Domb \& Pagel 2001) and the graded-signal hypothesis (Nunn 1999) are among the most prominent. Since female body size is correlated with swelling size, but swelling size is also independently associated with inter-birth intervals among these baboons, swellings may provide males with reliable indicators of female fertility histories as suggested by Domb \& Pagel (2001). Females with smaller swellings during the fully tumescent phase also had longer cycling phase durations, in line with the predictions of the reliable indicator hypothesis.

\section{Materials and Methods}

The study subjects were 23 female olive baboons, housed in two social groups at the CNRS (Centre National de la Recherche Scientifique) Primatology Station, France. All the females in this study were multiparous, healthy, reproducing, and weaning naturally. In terms of body composition and general health, all were larger than wild peers, with a mean body mass of $16.9 \pm 2.0 \mathrm{~kg}$ (range $=13.5-21.1 \mathrm{~kg}$ ). Observations took place over a period of 27 months from October 2002 through December 2004 (Garcia 2005). Females were systematically observed daily over 2 years and reproductive characteristics were recorded, including menstruation and morphological changes of the sex skin of the AGA.

\section{Animals, housing, and diet}

The composition of each group varied, with 63 individuals ( 2 adult males, 17 adult females, 2 adolescent females, 33 juveniles, and 9 infants) in park 2, in a $220 \mathrm{~m}^{2}$ enclosure with climbing apparatus and an inner compartment. The second group consisted of 97 individuals ( 2 adult males, 1 sub-adult male, 30 adult females, 2 adolescent females, 49 juveniles, and 13 infants) in park 5 , which measured $470 \mathrm{~m}^{2}$, again with both indoor and outdoor areas and a variety of enrichment objects. Eight females were sampled from park 2 and 15 from park 5; relative densities and group composition were similar between the parks. The groups had been formed for at least 2 years before the beginning of the initial study and thus all individuals were familiar with each other, and some matrilines (mothers and juveniles) had begun to develop (see also Garcia et al. 2006 for further details).

Baboons had free access to water and were scatter fed thrice daily with fresh fruits, vegetables, and two types of commercial monkey pellets (SDS, Vigny, France; UAR, Villemoisson-surOrge, France). Metabolizable energy value of SDS pellets was $11.9 \mathrm{MJ} / \mathrm{kg}$ and that of the UAR diet was $14.2 \mathrm{MJ} / \mathrm{kg}$. Fruit energy was determined by weighing different specimens over time and using averages of metabolizable energy per gram. Individuals in both parks had access to an equivalent quantity of food on a daily basis $(0.59 \mathrm{~kg} /$ individual in park 2 and $0.56 \mathrm{~kg} /$ individual in park 5), and nutrient intake of focal females was monitored (Garcia 2005). The number of each type of pellet and quantity and size of carrots and apples consumed by an individual were recorded during continuous focal samples, which started when food was distributed and terminated when all food was eaten. These samples were used to estimate individual energy intake over a 24-h period (MJ/day).

\section{Variables recorded}

Age

Age was determined from dental estimates of age when the animals arrived at the CNRS Primatology Station, and their previous reproductive history if known. The subject females ranged in age from 10 to 21 years, with a mean of $13.9 \pm 2.8$ years. They were categorized into one of three age classes (Smuts \& Nicolson 1989), and primiparous females under 8 years were excluded: 
- Younger middle-aged ( $~ 9-12$ years): age class $1(N=8$, four females in park 2 and four in park 5)

- Older middle-aged ( $\sim 13-16$ years): age class $2(N=11$, three females in park 2 and eight in park 5)

- Old and very old ( $>17$ years): age class $3(N=4$, one female in park 2 and three in park 5).

\section{Rank}

Female dominance rank was assessed as part of long-term behavioral monitoring over 3 years (2002-2004) using sampling of directionality of aggressive interactions ad libitum (Altmann 1974). Rank was based on the initiation and subsequent outcomes of all occurrences of dyadic approach-avoid and agonistic interactions (for more details, see Garcia et al. 2006).

Female rank was expressed as the proportion of females dominated (after Cheney et al. 1988), providing a relative rank ranging between 0 (low rank) and 1 (high rank), which accounted for differing numbers of females and thus was relatively comparable across the two parks. Rank was categorized on the basis of quartiles: high=upper quartile, $\mathrm{mid}=$ inter-quartile range, and low $=$ lower quartile. If rank is not highly linear, but rather, power is skewed, the arbitrary division of females into quartiles will obscure potential differences between 'alpha' individuals and a mass of relatively similar subordinate females. However, for the purposes of comparison with other studies, these high, mid, and low classes were used.

\section{Reproductive parameters}

The olive baboon has one of the largest and most conspicuous swellings of the $\sim 20$ anthropoid species with obvious sexual swellings during their menstrual cycle (Dixson 1983). The swelling affects the sex skin of the AGA. During the follicular phase of the menstrual cycle, the AGA increases in turgescence due to estrogenic stimulation (Dixson 1998). Ovulation occurs during the last few days of maximal tumescence (Hendrickx \& Kraemer 1969, Koyama et al. 1977, Shaikh et al. 1982), typically 2 days before the swelling subsides. After ovulation, this decrease in swelling size coincides with a post-ovulatory rise in progesterone and a decrease in estrogen concentrations (Stevens 1997).

AGA characteristics recorded and analyzed here were:

- post-menstrual flat (immediately following menstruation, AGA is flat and uncolored),

- moderate genital swelling (reddening or partial tumescence of the AGA),

- large genital swelling (the volume of the swelling is maximal and bright pink),

- deflating swelling (the volume of the swelling decreases to a moderate size. The onset of detumescence was recognized from the appearance of wrinkles, loss of coloration, and reduction of visible tumescence),

- full detumescence (no tumescence and pale colored).

Cycle length was calculated from the first day of menstruation to the subsequent first day of menstruation. The follicular phase was defined as the interval between the first day of menstruation and the estimated day of ovulation ( 2 days before detumescence), whereas the luteal phase comprised the period between the day of ovulation and the day before the next menstruation.

Females were observed daily from the birth of their infant and entered the sample as soon they started to exhibit sexual cycle activity. The first cycle after a birth was called the first postpartum cycle. Latency to cycling averaged 145 days (Garcia et al. 2006). Our analyses here focus on the duration of menstrual cycles and the duration of follicular and luteal phases within cycles. In addition, we explore the occurrence of conception; the day of conception was calculated as 2 days before detumescence. The conceptive cycle was defined as the cycle prior to the onset of pink coloration of the paracallosal skin of females, indicating pregnancy (Altmann 1970).

We could not, in this study, collect fecal data for reproductive hormone assay. Entry to the large enclosures with free-ranging groups was not possible; there were no areas where individuals could be confined during dung collection and the aim was to ensure that the animals were disrupted as little as possible. Reproductive data in relation to swellings have been exceptionally well documented for baboons from blood samples and vaginal swabs (Stevens et al. 1970, Kling \& Westfahl 1978, Shaikh et al. 1982, Bambra 1993). Such data may be more direct in their association with AGA swelling than are fecally recovered hormones which have both gut passage time lags and variance associated with diets (Wasser et al. 1993, 1994). Since we are not attempting to match individual swellings to individual hormone profiles in this paper, we rely on the well-established general profiles for follicular and luteal phases. In addition, these 23 females were the only possible subjects for inclusion in the study, as they were all breeding and weaning naturally.

\section{Anthropometric measurements}

Anthropometric measures were carried out on anesthetized females. All females in the sample $(N=23)$ were anesthetized once, as close to 4 weeks after their resumption of cycling as possible. They were anesthetized with ketamine $(10 \mathrm{mg} / \mathrm{kg}$ by i.m. injection), a widely accepted dissociative anesthetic used in studies requiring transient animal tranquillization. During anesthesia, the females were weighed with a standard scale (accurate to the nearest $50 \mathrm{~g}$ ) and measured for CRL, and the females were then placed with their infants in a recovery cage. The same investigators (C G, L R) were responsible for all body measurements to minimize inter-observer error. CRL was the distance in centimeters between the highest point on the head to the ischial callosities and was measured with a supine-length measuring table. The absolute size of the anogenital swelling was measured for 19 out of 23 females at the 4-5 weeks postpartum anesthesia. The swelling width was measured as the maximum length of the paracallosal skin. This swelling size parameter was the distance in centimeters between the right and left extremities (at the limit ischial callosities-hair), and was measured with an accuracy of one decimal.

\section{Ethical considerations}

All manipulations and treatments of the subjects had ethical approval from the Comité Regional d'Ethique sur I'Expérimentation Animale (Marseille, France) and followed European Science 
Foundation animal handling guidelines to minimize pain and distress. Since the aim of the study was to assess normative reproductive behavior in the social context, the social separation stress to the female and its infant was minimized. Trapping and measurements were considered to be interventions, but not invasive procedures.

\section{Statistical analysis}

Shapiro-Wilks tests were used to examine normality of the dataset. Where data were not normally distributed, we log transformed duration variables for use with parametric statistics. We explored variation among cycles for individual females using repeated measures tests on logged data, although there was high natural variation in the number of repeats (from 0 to 9) among females. For data that could not be normalized, we used nonparametric Mann-Whitney $U$ tests in comparisons between groups of females and Spearman $r_{\mathrm{s}}$ for correlations. We present means, medians, and IQR for data. When data (such as duration of a specific cycle phase) were missing for any individual female, it would be excluded from relevant analyses, although it might contribute to other analyses where data were available. Thus, sample sizes vary in the different statistical tests.

All statistical analyses were performed with SPSS for Windows version 11 (SPSS Inc., Chicago, IL, USA) with the significance level set at $P<0.05$.

\section{Acknowledgements}

This study was supported by CNRS GDR 2655 (Programme for energetics and adaptation of Hominidae). We thank Guy Dubreuil for allowing our research to be carried out at the CNRS Primatology Station, and animal keepers for field assistance. We also thank the referees for their helpful comments on the manuscript. The authors declare that there is no conflict of interest that would prejudice the impartiality of this scientific work.

\section{References}

Abbott DH 1992 Social conflict and reproductive suppression in marmoset and tamarin monkeys. In Primate Social Conflict, pp 331-373. Eds WA Mason \& SP Mendoza. New York: SUNY Press.

Altmann SA 1970 The pregnancy sign in savannah baboons. Laboratory Animal Digest 6 7-10.

Altmann J 1974 Observational study of behavior: sampling methods. Behaviour 49 227-267.

Altmann J, Hausfater G \& Altmann SA 1988 Determinants of reproductive success in savannah baboons, Papio cynocephalus. In Reproductive Success, pp 403-418. Ed. TH Clutton-Brock. Chicago: University of Chicago Press.

Bambra C 1993 Veterinary management and research techniques for reproductive studies in the baboon: a practical approach. Ed. C Bambra. Nairobi: National Museums of Kenya.

Bercovitch FB 1987 Female weight and reproductive condition in a population of olive baboons (Papio anubis). American Journal of Primatology 12 189-195.

Bonde JPE, Ernst E, Jensen TK, Hjollund NH, Kolstad H, Henriksen TB, Scheike T, Giwercman A, Olsen J \& Skakkebaek NE 1998 Relation between semen quality and fertility: a population-based study of 430 firstpregnancy planners. Lancet 352 1172-1177.
Breen KM \& Karsch FJ 2006 New insights regarding glucocorticoids, stress and gonadotropin suppression. Frontiers in Neuroendocrinology 27 233-245.

Breen KM, Billings HJ, Wagenmaker ER, Wessinger EW \& Karsch FJ 2005 Endocrine basis for disruptive effects of cortisol on preovulatory events. Endocrinology 146 2107-2115.

Cameron JL 1997 Stress and behaviorally induced reproductive dysfunction in primates. Seminars in Reproductive Endocrinology 15 37-45.

Cameron JL \& Nosbisch C 1991 Suppression of pulsatile luteinizing hormone and testosterone secretion during short term food restriction in the adult male rhesus monkey (Macaca mulatta). Endocrinology 128 1532-1540.

Cameron JL, Weltzin TE, McConaha C, Helmreich DL \& Kaye WH 1991 Slowing of pulsatile luteinizing hormone secretion in men after forty-eight hours of fasting. Journal of Clinical Endocrinology and Metabolism 73 35-41.

Chen EC \& Brzyski RG 1999 Exercise and reproductive dysfunction. Fertility and Sterility 71 1-6.

Cheney DL, Seyfarth RM, Andelman SJ \& Lee PC 1988 Reproductive success in vervet monkeys. In Reproductive Success, pp 384-402. Ed. TH CluttonBrock. Chicago: University of Chicago Press.

Chrousos GP, Torpy DJ \& Gold PW 1998 Interactions between the hypothalamic-pituitary-adrenal axis and the female reproductive system: clinical implications. Annals of Internal Medicine 129 229-240.

Dewey KG 1998 Effects of maternal caloric restriction and exercise during lactation. Journal of Nutrition 128 386S-389S.

D'Hooghe TM, Hill JA \& Mwenda JM 2004 A critical review of the use and application of the baboon as a model for research in women's reproductive health. Gynecologic and Obstetric Investigation 57 5-6.

Dixson AF 1983 Observations on the evolution and behavioral significance of "sexual skin in female primates". Advances in the Study of Behavior 13 63-106.

Dixson AF 1998 Primate Sexuality: Comparative Studies of the Prosimians, Monkeys, Apes and Human Beings, Oxford: Oxford University Press.

Domb LG \& Pagel M 2001 Sexual swellings advertise female quality in wild baboons. Nature 410 204-206.

Fenster L, Waller K, Chen J, Hubbard AE, Windham GC, Elkin E \& Swan S 1999 Psychological stress in the workplace and menstrual function. American Journal of Epidemiology 149 127-134.

Ferin M 1999 Stress and the reproductive cycle. Journal of Clinical Endocrinology and Metabolism 84 1768-1774.

Garcia C 2005 Energétique et régulation de la fonction de reproduction chez des femelles captives babouins olive (Papio anubis). PhD thesis. Université d'Aix-Marseille II, France.

Garcia C, Lee PC \& Rosetta L 2006 Dominance and reproductive rates in captive female olive baboons, Papio anubis. American Journal of Physical Anthropology 131 64-72.

Gesquiere LR, Wango EO, Alberts SC \& Altmann J 2007 Mechanisms of sexual selection: sexual swellings and estrogen concentrations as fertility indicators and cues for male consort decisions in wild baboons. Hormones and Behavior 51 114-125.

Girolami L \& Bielert C 1987 Female perineal swelling and its effect on male sexual arousal: an apparent sexual releaser in the chacma baboon (Papio ursinus). International Journal of Primatology 8 651-661.

Harlow SD \& Campbell B 1996 Ethnic differences in the duration and amount of menstrual bleeding during the postmenarcheal period. American Journal of Epidemiology 144 980-988.

Hendrickx AG \& Kraemer DC 1969 Observations of the menstrual cycle, optimal mating time and preimplantation embryos of the baboon, Papio anubis and Papio cynocephalus. Journal of Reproduction and Fertility 6 119-128.

Kling OR \& Westfahl PK 1978 Steroid changes during the menstrual cycle of the baboon (Papio cynocephalus) and human. Biology of Reproduction 18 392-400.

Koyama T, De La Pena A \& Hagino N 1977 Plasma estrogen, progestin, and luteinizing hormone during the normal menstrual cycle in the baboon: role of luteinizing hormone. American Journal of Obstetrics and Gynecology 127 67-72.

Loucks AB, Mortola JF, Girton L \& Yen SS 1989 Alterations in the hypothalamic-pituitary-ovarian and the hypothalamic-pituitary-adrenal axes in athletic women. Journal of Clinical Endocrinology and Metabolism $68402-411$. 
Martin LJ, Carey KD \& Comuzzie AG 2003 Variation in menstrual cycle length and cessation of menstruation in captive raised baboons. Mechanisms of Ageing and Development 124 865-871.

Nunn CL 1999 The evolution of exaggerated sexual swellings in primates and the graded-signal hypothesis. Animal Behaviour 58 229-246.

Packer C, Collins DA, Sindimwo A \& Goodall J 1995 Reproductive constraints on aggressive competition in female baboons. Nature 373 60-63.

Rosetta L 1993 Female reproductive dysfunction and intense physical training. Oxford Reviews of Reproductive Biology 15 113-141.

Rosetta L, Harrison GA \& Read GF 1998 Ovarian impairments of female recreational distance runners during a season of training. Annals of Human Biology 25 345-357.

Rowland AS, Baird DD, Long S, Wegienka G, Harlow SD, Alavanja M \& Sandler DP 2002 Influence of medical conditions and lifestyle factors on the menstrual cycle. Epidemiology 13 668-674.

Sanders KA \& Bruce NW 1999 Psychosocial stress and the menstrual cycle. Journal of Biosocial Science 31 393-402.

van Schaikh CP, van Noordwijk MA \& Nunn CL 1999 Sex and social evolution in primates. In Comparative Primate Socio-Ecology, pp 204-240. Ed. PC Lee. Cambridge: Cambridge University Press.

Setchell JM \& Wickings EJ 2004 Social and seasonal influences on the reproductive cycle in female mandrills (Mandrillus sphinx). American Journal of Physical Anthropology 125 73-84.

Shaikh AA, Celaya CL, Gomez I \& Shaikh SA 1982 Temporal relationship of hormonal peaks to ovulation and skin deturgescence in the baboon. Primates 23 444-452.

Shrestha HK, Nakao T, Suzuki T, Higaki T \& Akita M 2004 Effects of abnormal ovarian cycles during pre-service period post-partum on subsequent reproductive performance of high-producing Holstein cows. Theriogenology 61 1559-1571.

Small CM, Manatunga AK, Klein M, Feigelson HS, Dominguez CE, McChesney R \& Marcus M 2006 Menstrual cycle characteristics: associations with fertility and spontaneous abortion. Epidemiology $\mathbf{1 7}$ 52-60.

Smuts B \& Nicolson N 1989 Reproduction in wild female olive baboons. American Journal of Primatology 19 229-246.

Stallmann RR \& Froehlich JW 2000 Primate sexual swellings as coevolved signal systems. Primates 41 1-16.

Stevens VC 1997 Some reproductive studies in the baboon. Human Reproduction Update 3 533-540.

Stevens VC, Sparks SJ \& Powell JE 1970 Levels of estrogens, progestogens and luteinizing hormone during the menstrual cycle of the baboon. Endocrinology 87 658-666.

Strum SC \& Western JD 1982 Variations in fecundity with age and environment in olive baboons (Papio anubis). American Journal of Primatology 3 61-76.
Thierry B, Heistermann M, Aujard F \& Hodges JK 1996 Long-term data on basic reproductive parameters and evaluation of endocrine, morphological, and behavioral measures for monitoring reproductive status in a group of semifree-ranging Tonkean macaques (Macaca tonkeana). American Journal of Primatology 39 47-62.

Vitzthum VJ, Spielvogel H, Caceres E \& Miller A 2001 Vaginal bleeding patterns among rural highland Bolivian women: relationship to fecundity and fetal loss. Contraception 64 319-325.

Wade GN, Schneider JE \& Li HY 1996 Control of fertility by metabolic cues. American Journal of Physiology 270 E1-E19.

Wang L, Wang X, Wang W, Chen C, Ronnennberg AG, Guang W, Huang A, Fang Z, Zang T, Wang L et al. 2004 Stress and dysmenorrhoea: a population based prospective study. Occupational and Environmental Medicine 61 1021-1026.

Wasser SK, Thomas R, Nair PP, Guidry C, Southers J, Lucas J, Wildt DE \& Montfort SL 1993 Effects of dietary fibre on faecal steroid measurements in baboons (Papio cynocephalus cynocephalus). Journal of Reproduction and Fertility 97 569-574.

Wasser SK, Montfort SL, Southers J \& Wildt DE 1994 Excretion rates and metabolites of oestradiol and progesterone in baboon (Papio cynocephalus cynocephalus) faeces. Journal of Reproduction and Fertility 101 213-220.

Wasser SK, Norton GW, Rhine RJ, Klein N \& Kleindorfer S 1998 Ageing and social rank effects on the reproductive system of free-ranging yellow baboons (Papio cynocephalus) at Mikumi National Park, Tanzania. Human Reproduction Update 4 430-438.

Williams NI, Caston-Balderrama AL, Helmreich DL, Parfitt DB, Nosbisch C \& Cameron JL 2001 Longitudinal changes in reproductive hormones and menstrual cyclicity in cynomolgus monkeys during strenuous exercise training: abrupt transition to exercise-induced amenorrhea. Endocrinology 142 2381-2389.

Xiao E, Xia-Zhang L \& Ferin M 1999 Stress and the menstrual cycle: shortand long-term response to a five-day endotoxin challenge during the luteal phase in the rhesus monkey. Journal of Clinical Endocrinology and Metabolism 84 623-626.

Xiao E, Xia-Zhang L \& Ferin M 2002 Inadequate luteal function is the initial clinical cyclic defect in a 12-day stress model that includes a psychogenic component in the rhesus monkey. Journal of Clinical Endocrinology and Metabolism 87 2232-2237.

Received 8 November 2006

First decision 6 March 2007

Revised manuscript received 13 July 2007

Accepted 10 October 2007 